\title{
Simulated or Reproduced Reality Events as the Basis of Reflective Learning
}

\author{
Rachel Wlodarsky ${ }^{1, *}$, Howard Walters ${ }^{2}$, Paula Baughn ${ }^{3}$ \\ ${ }^{1}$ College of Education and Human Services, Cleveland State University, Cleveland, USA \\ ${ }^{2}$ College of Education, Ashland University, Ashland, USA \\ ${ }^{3}$ College of Education and Human Services Doctoral Studies, Cleveland State University, Cleveland, USA
}

\section{Email address:}

r.wlodarsky@csuohio.edu (R. Wlodarsky), hwalters@ashland.edu (H. Walters),p.baughn@vikes.csuohio.edu (P. Baughn)

${ }^{*}$ Corresponding author

\section{To cite this article:}

Rachel Wlodarsky, Howard Walters, Paula Baughn. Simulated or Reproduced Reality Events as the Basis of Reflective Learning. International Journal of Psychological and Brain Sciences. Vol. 4, No. 4, 2019, pp. 41-49. doi: 10.11648/j.ijpbs.20190404.11

Received: July 9, 2019; Accepted: August 14, 2019; Published: August 29, 2019

\begin{abstract}
Within the literature, the authors observe a common pattern of learner reaction to simulations. Learners engage in simulated events that is similar to that which would be encountered in the real world. There is a translation, through cognition, of the simulated experience to real-world-learning, in a way that directly situates the learners for reengagement of the real world beyond the simulation. In the current study, the authors have linked these observations to a new set of response data from a study of university professors, in an effort to understand, develop, and support personal and professional development strategies and opportunities for professors across the university. A voluntary sample comprised of 40 professors from two different universities in the Midwest, were asked in a survey to define reflection and discuss cognitive processes that facilitated reflection on their own professional development. A constant comparative procedure, a qualitative coding strategy, was used to examine the data collected and the data were coded for clusters of similar behaviors. This coding was converted to visual representation using concept mapping techniques. A preponderance of participants used the same reflective process to consider, evaluate, describe and structure their professional activities, which began with an experience-an event-of practice and was clearly a precipitating experience linked to a subsequent cognitive processing. For many participants, the event serving as the basis for reflection is not grounded in an historical, real-world or authentic experience; but rather there was a shift to use of simulated or reproduced events that is clear and significant. It seems clear from the authors' research findings and that of others cited in this paper, that simulations of experience possess the ability to transfer to real-world growth, development, and decision-making and would be preferred for vocational education uses over the reliance on authentic field and clinical experiences. Consideration of simulations as an experiential method for professional growth and development efforts seems, in this analysis, quite more complex an issue when one considers the implications of linguistics and language development to behavioral coding; the uses of cognitive tools to aid learning; and the manner in which language itself shapes, empowers or impedes the embedding of experience into human memory - and activates that memory for professional and personal action. The authors perceive that, while much progress has been made in highlighting these issues and their relationships, much work remains ahead.
\end{abstract}

Keywords: Simulated Experiences, Authentic Experiences, Reflection, Cognitive Processing, Learning from Experience, Clinical, Field Experiences

\section{Introduction}

Much of the perception of learning from experiences, through a reflective, cognitive response to those experiences, is situated in a philosophical position elucidated most clearly by Habermas [5]. With the emergence of transcendental philosophy, Habermas [5] writes that the task of knowledge construction is the "discovery of deep-seated structures in the background of the lifeworld. These structures are embodied in the practices and activities of subjects capable of speech and action" (p. 11). At core, this process involves linking the 
lifeworld-lived experiences - to knowledge about that world through a somewhat systematic structuring process. Commonly, this phenomena is described as learning from experience. For Habermas [5], this process is mediated with and through language: "After the linguistic turn, we no longer have access to an internal or external reality that is not linguistically mediated. The presumed immediacy of sense impressions no longer serves as an infallible court of appeal. Absent the possibility of a recourse to uninterpreted sense data, sense experience loses its unquestioned authority. In its place, there is the authority of 'second-order experience' that is possible only for an acting subject." (p. 12). Lyotard [11] would describe the loss of recourse to uninterpreted sense data as a transition from narrative epistemology toward a more structural or positivist epistemology —utilizing external evidences or data to describe experience [11] and engendered by cognition. In this view, internal sensory judgments grow insubstantial. Remembrances and reflections must become cognitive, or be cognitively processed and accessed, and be based out of justified knowledges, a position coherent with Habermas [5].

Habermas [5] suggests that experiencing failure, which he describes as "a disconnect between beliefs and intentions," and performance in the face-of-reality, creates a tension in the mind of the individual that motivates a search for meaning and truth in pragmatic terms. In an earlier paper, the author described this as cognitive tension that emerged from a critical experience that was unsatisfactory. Returning to his study [5], later, in concluding this discussion, Habermas notes, “...creative problem solving, caused by disturbances in routine practices (cognitive tension), is what makes us change our beliefs. These beliefs in turn are fallible and subject to confirmation. From a pragmatics point of view, 'cognition' results from the intelligent processing of performatively experienced frustrations.” (p. 13).

This, the authors believe, underlines what they've termed perplexity about a problem, and explains the motivation toward critical problem solving apparent in the framing of reflection in the body of their work on reflection on professional practice.

And so, to summarize: there is a philosophical and practical gap between real world experience and simulations of real experiences (as will be expanded on below). This gap is problematized further by the inadequacy of direct sensory reaction to real experiences. Over time, our sense responses grow less reliable for a variety of reasons such as forgetfulness and the loss of emotional weight, as well as the distortions of our own biases. As direct sense response to authentic experiences is therefore problematic, it may be valuable to consider an alternative: the possibility that simulations of direct (real) experiences could be more effectively and efficiently contrived and managed to support that secondary cognitive analysis toward the same effect. In short, simulated experiences may be as valuable for reflection on practice and action as real world, authentic experiences given the limitations of these as discussed above.

\section{Theoretical Background}

There is a rich literature, across a wide range of professional and vocational endeavors, that has considered the exploitation of simulation as a learning tool for adult learners and professionals. While these various cases incorporating reality simulations, which the authors summarize below, cover a widely disparate set of contexts, each case demonstrates a compelling and interesting pattern. The learner, sometimes a student, sometimes a professional, engages in a simulation of a desired real-world event or decision. In each case, researchers have observed emotional, reflective, cognitive, and real-world responses that mirror responses that have occurred through real world experiences. And in each case, these responses to simulated events produce observable, real-world behavior changes in the desired direction of improvement of professional behaviors. The authors will first summarize these cases, then follow with evidence from their own current research that demonstrates the same pattern, then return to a discussion of the implications of this simulation of experience phenomena to the question of learning from reflection on experience.

\subsection{Sim City}

An ethnographic study of SimCity with a single secondary education licensure class at a university in Spain, investigated information processing among ten adult students and their instructor creating cities in the simulation [13]. In SimCity, no clear objective exists to determine a winner. An analysis of discourse in these course sessions indicated the teacher and adult students created their own goals and implemented their own conditions for play. In this sense, this aspect of simulation is quite distinct from the control possible in the real world of construction. Participants also guided each other through various issues that arose during play events, including troubles navigating the controllers, game menus and other aspects of the technology as well as goals for the simulation. Monjelat, Mendez-Zaballos, and Lacasa [13] also "observed that the teacher's internal representation, based on his own experience as a player, served both as an external representation for students, and as an inherent condition of the problem, since he defined the problem space" (p. 1515).

In research conducted by [12], SimCity was also used in two urban planning courses, one bachelor's and one master's level, at a university in Australia [12]. In addition to dealing with initial technical difficulties, the students often did not create realistic cities. Minnery and Searle [12] found that most students categorized their experiences with the simulation as negative, though the difficulties they encountered could be interpreted to result in positive learning "in that they reinforced student awareness of the complexity of factors involved in real-life" (p. 47). The students struggled with the practicality of program assumptions, limitations and other parameters. Several postgraduates in particular, who had professional experience, cited the lack of realism in the simulation as source for some of their 
frustrations. The authors conclude connecting the simulation to other lessons, like understanding utopian visions, was more successful [12].

The use of the computer game SimCity in one urban geography course stimulated creative and critical thinking and connections among theory and practice [6] for nearly thirty students, mostly sophomores, at a South Korean university. Members of the class also expressed difficulties in learning the technology [6] and in constructing the cities they envisioned with the simulated system in their evaluations, which included a reflective paper, portfolio, presentation, and interviews. Kim and Shin [6] cite the research by Minnery and Searle [12] in signifying "the students' frustration with failing to complete their initial plans may be part of the essential learning that makes them aware of real-world situations" (p. 43). The authors also suggest that in becoming discouraged, the students were motivated to more critically evaluate "the underlying logic and process of the SimCity functioning" [6]. Of interest to the current authors in this case is the observation of discouragement, failure, and critical evaluation of performance as a result of simulation, and how these were linked to future engagement in real world practices.

Lin and Lin [9] conducted in-depth laddering interviews with fifty college graduate users of SimCity and identified four main chains involving multiple attributes of the game. These routes of learning included ten learning consequences, ranging from organizational thinking to imagination and creativity to problem-solving; and concluded with the four main values of sense of accomplishment, self-fulfillment, fun and enjoyment, and self-respect. The researchers posited differences among paths for players with majors in engineering and science, who tended to emphasize consequences with "products" [9], compared to those with degrees in humanities and social sciences, who focused more on experiences and understanding. Distinctions also were suggested for graduate and undergraduate degree holders, with the former more likely to gain experience and the latter to gradually build knowledge through the game. The authors contend the main learning result across players, however, was cultivation of imagination and creativity because the event is still only a simulation of establishing a city [9].

In each of these cases involving the use and study of SimCity, even though the participants were only engaged in simulation, a range of emotional responses were observed that revealed the powerful effect of this simulation software to produce real-world reactions (Habermas' [5] sensory responses). These sensory responses were in most cases processed and connected to other, real-world applications for the various groups of participants involved: to critical and creative problem solving in the real world. This reflects the transition from simulation to authenticity, and from sensory reaction to cognitive reflection on experience described by Habermas and Lyotard [5, 10] earlier.

\subsection{Business and Engineering Gaming}

Wills and Clerkin [19] contend that an undergraduate business course that combines an online simulation Business Strategy Game with reflective practices has led to improved connections between theory and practice during the experience in which students simulate operating an athletic footwear company, because of the addition of thoughtfully recounting decisions throughout the gaming event. According to the authors, the students' enhanced decisionmaking and transactions at an enterprise level led to a statistically significant number of competition wins for the teams from the small regional public university campus in the Midwest compared to other teams in the international competitions over the course of four years [19].

Mawdesley, Long, Al-jibouri and Scott [11] added reflective practices to increase student engagement and completion with two simulations, the Muck and Canal games, used in a master's level engineering course in Applied Construction Project Management at a university in the Netherlands. The authors report that learning was enhanced by the addition of voluntary small group presentations and discussions, with students indicating they could improve their own performance based on other groups' analysis as well as with their self-evaluations [11]. The researchers also administered a questionnaire before and after the addition of a teaching module and reported "more detailed and insightful replies" from the students following the instruction [11] and posit that they intend to add a reflective project diary throughout the module in the future.

In these two gaming situations, as observed in SimCity above, business students and engineering students participated in simulation gaming that modeled decisionmaking that would typically be required of professionals in authentic professional practice. And again, in each case, a transfer was observed from the simulation to authentic problem solving following the gaming. The simulations effectively modeled reality, it seems, because-as Habermas [5] and Lyotard [10] discuss-the usefulness of direct sensory response to authentic experience is overly problematic in any regard, and must yield to a secondary translation for cognitive, reflective use.

\subsection{Students and Classroom Teachers}

In an action research project involving an online professional development seminar, teachers utilizing the Jewish Court of All Time (JCAT) online character simulation in their middle school classes described themselves as both teachers using the tool and students of the game in their reflections [15]. The role playing in JCAT added another dual dimension for the teachers to manage: They were instructors advising their classes in the simulation and were also allowed to assume and play characters in the game unbeknownst to the students in their classes. "This position also transformed the relationships between students and teachers as they were 'in' the learning together" [15]. These teachers reflected on their positions as teachers in juggling their "sense of responsibility to curriculum and context" in classroom practice [15] as well as to the process and objectives of the game. The authors used both synchronous and asynchronous 
sessions during the seminar and reported thoughtful reflections from teachers in both modalities. They revealed not only insights about themselves as teachers and learners but also as advocates for self [15]. The simulation also included graduate student mentors for the middle school students, and the teachers expressed how these teaching assistants could support their leadership of the course as well as the students in [15]. The teachers also expressed how they had observed the students taking part in the simulation were more engaged in writing activities and discussing aspects of the course outside of classrooms (italics added for emphasis) [15].

Teacher candidates in two sections of an elementary education preparation course simulated teaching activities in both the roles of instructors and as students and completed critical reflections as part of an action research project at a public university in Venezuela [8]. In the course focusing on natural science and health education teaching methodology, the student-teachers-in-training rehearsed learning activities using science and technology resources. They then gave oral presentations and provided written accounts of the events. Lacueva [8] posits the students' verbal insights tended to be of better quality than their "more distant and succinct" ( $\mathrm{p}$. 204) compositions. In evaluations at the end of the course, multiple candidates emphasized how these experiences with reflection enhanced their preparation as future practitioners [9]. The authors conclude these "experiences were the ones that the students considered the most valuable [9]. It is important to note that these reactions were to reflection on simulations, not reflection on authentic field practice. The education students also selected and prepared lessons related to actual elementary science and health curricula and then enacted them as if they were students, then discussed and reflected on the simulation. Lacueva [8] indicated the candidates' practice of this "project like at school" (p. 208) focused on telling "documentary rather than empirical" aspects, which is typical for elementary school class performance [8]. At the end of the course, the teaching candidates also indicated this simulated event in which they assumed the position of the children they will teach was "one of the best activities of the course for its usefulness and enjoyable nature" [8].

In an additional case, fifty-seven American educators in an ESL education master's program conducted teaching sessions in Spanish with public elementary primary school classes in Mexico during an international in-service experience [4]. The teachers wrote in Spanish about their favorite aspects, composed additional reflections in English, and participated in simulation debriefing. Researchers identified themes of affect or emotion, cognitive processes, and relation to teaching in the accounts. Again, the authors note the relation of the earlier summary of Habermas [5] and Lyotard [10] in the presence of both initial sensory response, then secondary cognitive processing. In addition to concerns about writing in their nonnative language, more than $80 \%$ of the educators expressed "feelings of anxiety, fear, confusion, doubt, failure, and anger" [4] with regard to the teaching event. They also expressed confidence in connecting the experience to their own teaching practices and with a better understanding for students learning in their U.S. classrooms out of these simulations. Cognitive strategies were most often cited with regard to the actual Spanish writing task. The authors conclude the setting, in Mexico, enhanced the relevance of the simulation [4].

\subsection{Health Care Professionals}

As a final case example of simulated reality, nearly all of the four-hundred medical faculty of varying experience levels from sixteen different teaching hospitals who attended a development workshop with precepting, micro-skill roleplay and debriefing session [18] indicated the activity added to their teaching or research abilities and would be useful to them in future practice.

Additionally, more than three-hundred respondents to a faculty development module for the National Health and Education Training Simulation program in Australia reported stories about their previous participation in simulation-based education events. Bearman, Greenhill, and Nestel [2] measured event stories and identified four kinds of narratives, with more than four out of every five relating to what was learned during the actual experience, so-called progress scenarios. In addition, about one out of five stories recounted "transformative" results that influenced practice for years to come following the simulation, and one in five discussed how the replicated "practice" imitated real situations (italics added for emphasis) [2]. Most stories simulated experiences from early in the health professionals' careers. Several participants revealed how the simulation activity helped them better grasp the benefits of the teaching method as authentic practice. Many also expressed negative emotional reactions to aspects that did not go as planned or experiences that were uncomfortable, but which the participants transformed into learning to create a positive outcome [2].

\section{The Study Case}

In each of these previous cases, the authors observe a common pattern of participant or learner reaction to the simulations. The learners engage in simulated events (realities, situations, role play, professional problem solving) that is similar to that which would be encountered in the real world. Even though these simulations are stripped of the risk of failure and consequence that would accompany authentic experiences in the real world, the learners nevertheless exhibit consistent positive and negative emotional reactions. There is a translation, through cognition, of the simulated experience to real-world-learning, in a way that directly situates the participants for reengagement of the real world beyond the simulation. In this way, the authors observe a modeling of the philosophical perspectives on reality and experience, emotional response and cognitive processing discussed by Habermas [5] and Lyotard [10] at the beginning of this paper. It seems that simulated events possess great 
value for preparation for real-world reflection and growth, and this is seen across a diverse set of professional and academic disciplines.

In the current study, the authors have linked these observations from these prior case examples to a new set of response data from a study of university professors, in an effort to understand, develop, and support personal and professional development strategies and opportunities for professors across the university.

\subsection{Population and Data}

Upon approval from both institutions' Institutional Review Board, a voluntary sample was recruited for the current study, comprised of forty professors from two different universities in the Midwest. The faculty members who participated in the study were members of colleges of Education, Human Services, Liberal Arts and Social Sciences, Business, Urban Affairs, and Nursing and Health Sciences. Located in Ohio, one university is a private, liberal arts institution of higher education guided by a religious heritage, which espouses core values such as individuality, character development, and excellence in teaching. The other university is an urban, public institution of higher education guided by scholarship and diversity in service to students and the surrounding community. The participants varied, ranging from tenure-track to tenured faculty, professional instructors and adjuncts who teach undergraduate and graduate courses. Some of these colleges implement a reflection-based model of annual faculty review and professional development.

All participants signed informed consent statements that explained the study and the intended use of their responses. The sample included individuals who selected to participate at an anonymous level-completing the survey only. Participants defined reflection and discussed cognitive processes that facilitated reflection on their own professional development. The specific survey item that generated the bulk of the narrative data read as follows:

Write out a brief definition of reflection and describe how this practice might relate to your professional development as a faculty member. As part of your definition, describe the tools you use to facilitate your reflection (s). Examples of tools include but are not limited to: portfolios, journal writing, student comments, peer feedback, course artifacts, discussions, inquiry questions, and video/audio-taping. Please indicate any other tools you have used to facilitate your reflection (s).

\subsection{Data Analysis}

A constant comparative procedure, a qualitative coding strategy, was used to examine the data collected through the survey described above. Initial themes and categories among the narrative responses were established as a first step in enhancing the credibility of the project. The themes which emerged have been observed in related literature, providing additional confirmatory support for reliability and credibility of the findings.
This procedure allowed the researchers to organize and label participant responses. The coding strategy, following Novak [14], treated words and phrases (grammatical units) as discrete conceptual units of equal weight. Based on a logicalrational use of vocabulary definitions, these conceptual units were then clustered to establish themes. These themes were then cross-walked to the literature cited in earlier publications to establish the reasonableness of the themes and to control for researcher bias. The researchers coded the first participant's survey responses separately, and then compared their results to standardize the coding process. Following agreement on the process to be used, two additional participants' responses were coded, and compared to monitor agreement on the process and consistency of coding, and finally the remaining sets of data were coded and mapped. It should be noted two faculty responses were too brief for meaningful analysis and were excluded from analysis. Analyses, as well as findings, were constructed and edited to protect the individual privacy of the participants.

\section{Findings}

The response data from the study participants were coded for clusters of similar behaviors, and this coding was converted to visual representation using concept mapping techniques. A preponderance of participants used the same reflective process to consider, evaluate, describe and structure their professional activities. A meta-map depicting the typical reflective path followed by the participants is presented below (Figure 1).

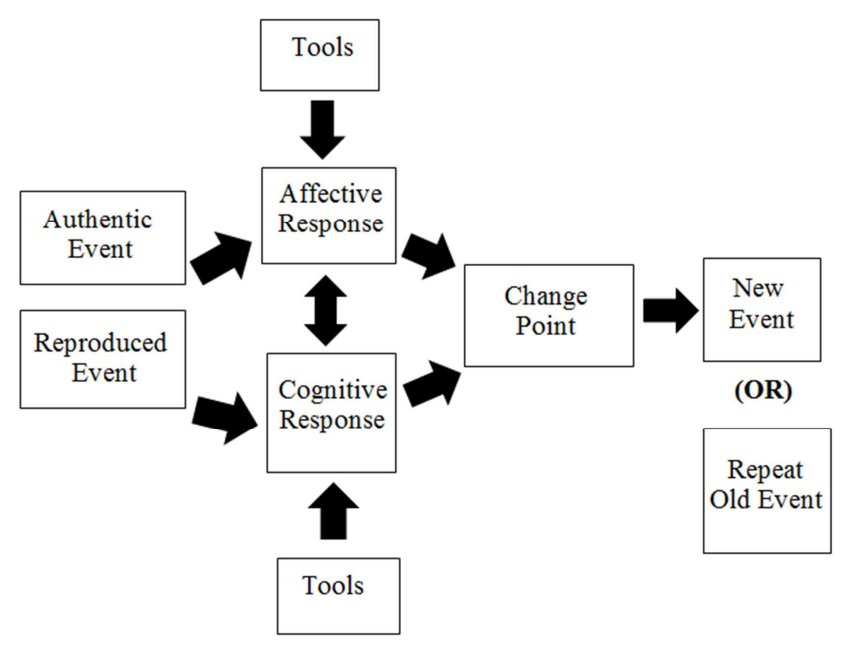

Figure 1. Revised event path for professional reflection.

This reflective path followed by the participants indicated a precipitating Event, authentic or simulated (or reproduced), followed by an intentional period of cognitive or affective processing of information. The Cognitive or Affective component served as the point in which some problem was formulated. This point is also what Habermas [5] described as the translation point, moving sensory data to linguistic information. The information processed during this period was derived from Tools, which is a form of data collection 
and cognitive processing by the participants. These cognitive elements are followed by a Change Point, where behavior is changed, based on a cognitive or affective decision.

\subsection{The Event and the Current Case Data}

For the participants in the current study, their process of professional development as college faculty members began with an experience-an event-of practice. This may have been a class session or a set of classes over a semester. The event may have been a set of reviewer comments on a manuscript submitted for publication. The event may have been student work, which became, for the professor, secondary evidence of his/her own professional performance. Nevertheless, for these professors, there was clearly a precipitating experience linked to a subsequent cognitive processing. This observation supports Schön's $[16,17]$ localization of the reflective act in practice itself, and not in technical rationality or knowledgeabout [16, 17]. Nevertheless, for many participants in the current study, the event serving as the basis for reflection is not grounded in an historical, real-world or authentic experience; but rather there was a shift to use of simulated or reproduced events that is clear and significant.

These simulated or reproduced events are observed, for example, in the reliance on other individual's reactions to or reflections on the participants' direct experiences, which are then communicated to the participants, who then use these as the basis of their own decision-making. As this particular study population was university faculty members, not coincidently this phenomena is first observed in the use of student evaluations and student feedback on course experiences. One professor wrote, "I ask students for their reaction to my teaching performance with an eye to improving both the student's experiences and outcomes." Another wrote that "tools that I use to facilitate my reflections include my student evaluations and overall student performance in my classes" ...performances by students are events that this faculty member experienced. Finally, another professor wrote, "I chat with students about their experiences in the course as well as examine student comments." These and many similar statements made by participants are categorically unique when considered as life events on which the participants are reflecting for purposes of growth and development. These types of student feedback centered narratives frame the heart of the evidence that these faculty members seem to use in professional self-analysis and self-awareness. There is a conspicuous absence from most narrative responses of the participants thinking about or reflecting upon their own personal experience of a class session.

There is evidence of use of peer feedback in ways that are similar to the feedback obtained and used from students in these participants' classes, and also related to the broader conduct of the professional tasks of faculty members, including publication and research. One participant described the use of feedback from a journal editor, "I reflect on the positive and negative feedback I receive from journal editors when my submissions are either accepted or rejected." Other participants leaned into peer observations or discussions about class settings. One participant wrote, "reflection is the act of considering what you do from an impartial perspective, instead of the perspective you take while engaging in what you do. Tools that help include hearing the perspectives of other teachers." This quote is interesting because it seems to qualify personal sense and emotional response, and even personal cognitive critique as biased and not always helpful to the process of reflection as an evaluative inquiry. The authors will return to this perception in later discussion, as it may frame an important element of the need to physically silence the personal voice from authentic experience expressed by many of these participants, and is something the authors have observed in previous research.

A final shift from first person response to real or authentic experience to a simulated level, where the response is to a simulated experience, is observed in the participants' incorporation of video recordings of authentically experienced class sessions or clinical sessions. One participant discussed her use of reflections based on informal conversations with both students and peers, but then added, "I plan to do some video self-reflections in the future." Another described professional growth in clinical therapeutic settings, "We taped client sessions for review in supervision sessions as a way to reflect" [on our practices.] Another participant characterized the value of such videotaping, "Videotaping is invaluable. You get a chance to see yourself in action and to pick up on things that occur in your class." The implication is that one does not really experience her own class when she is experiencing her class in real time and place conditions. This real experience can only emerge at a later time when one is watching the video recording. The video, in this example, models Habermas' [5] translation of primary, sensory experience to secondary cognitive processing. A final participant provided an interesting descriptive phrase associated to this videotaping approach, "Tools for reflection include unsolicited student feedback, peer evaluations and photos of events. I use these to, often, 'play' the video of the experience in my mind." This language is a fascinating example of distancing, or intentionally re-creating a simulated experience in her mind by "playing" memory as if playing a video recording. This is perhaps an overly honest effort to qualify the value of direct, authentic experiences by willful objectification, after the fact, of memory. Of reducing personal memory to only one of a number of sources of evidence that also include what others think. This seems to reflect both self-doubt, but also perhaps an awareness of the reality of unconscious bias in the manner in which we process sensory data from real experiences. This also supports the value of objectified, simulated (or reproduced) experiences.

\subsection{An Ontology of Event and the Emergence of Simulation}

Because of the criticality of experience, as noted in the case example and previous citations, as the precipitating or initiating first step toward reflection, the authors perceive a 
gap in the current literature for a sustained focus and discussion of the nature and characteristics of the event, and a discussion of the implications of a critical event or experience for professional development. Thus, the authors have developed a sequence of papers as a refinement of the reflection model described previously with this more nuanced and careful description of that first step in the reflective process.

In previous work, the authors have described two distinct categories of events; one is termed authentic, and the other simulated or reproduced, following Benjamin's [3] discussion of authenticity and reproduction of phenomena in his classic essay of 1934, Art in the Age of Mechanical Reproduction. Benjamin [3] describes the aura of an authentic object or phenomena as derived from its proximity in time and space to individual lives. The authors borrowed this terminology and discussion as it pertains to an evolving understanding of professional reflection. In Event Path for Professional Reflection manuscript, the process begins with an event. The authors did not argue that the authentic events or simulated (reproduced) events would or would not result in reflection.

The authors have avoided linking authenticity with objectivity/existential subjectivity in terms of truth claims and the interpretation of experience whether objective or subjective, in favor of linking authenticity to historicity (space and time). Thus, an event is construed as authentic when the individual is embedded in time and space with the event, which is thus directly apprehended through the senses. This is not to say that the individual's perception is not skewed by personal socio-cultural history. In fact, it is to assert exactly that: The authentic event is a nexus of the event itself, the individual, and the historical and sociocultural life of the individual articulating in a singularity [1] and is imbued with personal bias.

The case data above suggest that participants, when tasked at the meta-level to consider their own reflection on experience, are aware of the potential of this bias. Habermas [5] would assert that this is the rejection of sensory perception as the substantiation of belief. Justified conclusions are formed as perceptions, and made to conform to historical reality by a process of objectification, or as Habermas [5] described, translation to linguistic and cognitive processing. The authors concur.

For this current paper, an event is defined as simulated when the individual and his/her socio-cultural history is removed from a historical (time and space) relationship with the event itself such that it was not or cannot be experienced by that individual directly. Examples in the current case where individuals used these simulated or reproduced events are: reliance on adult student experiences, reliance on peer perspectives, reliance on editor reactions to manuscripts, and reduction of authentic class sessions to video reproductions or memories. Again, Benjamin [3] might suggest that the simulated event, in this instance, lacks the aura or patina of historical or biographical reference, but the participants rely on these, nevertheless, as if they maintained authority. On the basis - not of their own reaction to their experience but that of others - they make adaptive professional change decisions in the real world of practice.

As the authors have worked through several analyses and interpretations as well as a broad literary frame, they have developed a working definition of reflection:

Reflection is a multifaceted construct comprised from different types of events-authentic or simulated/reproduced-which are experienced both through and outside of the individual and his or her socio-cultural history. It is further understood that the cognitive process occurs on a continuum of subjective to objective based upon the tools incorporated in cognition.

Consequently, the distinction between the authentic and the simulated event results in a continuum from more subjective (authentic) or more objective (simulated) which is created from a singularity, or lack thereof, of the individual's socio-cultural history in time and space with the event. Likewise, the cognitive process is dichotomized into more subjective (a lack of information derived from the use of data collection tools) or more objective (through information derived from the use of data collection tools). In this sense, the authentic event (because it includes the socio-cultural history of the individual) is consequently more subjective. The simulated event (because it does not include the sociocultural history of the individual) is consequently more objectified. Cognition is then skewed more or less subjectively/objectively depending on the use of outside information collected systematically by the individual through the use of some cognitive tool. The authors are cautioned in their theorizing at this point, however, by the earlier caveat of Habermas [5] on the durability of sensory response to authentic events. Absent a translation of sensory experience to cognition through language, the value of the authentic experience is at least questionable.

Authentic events are already embedded in our personal histories and biographies by definition. We have directly lived these events. Simulated events are encountered secondarily at best with respect to our personal history and biography. These simulated events, however, serve as powerful and useful triggers for subsequent reflection and may lead to deep growth and reconceptualizations of both self and practice. The effect of these simulated events - if we may grasp a statistical metaphor-is diffused over less historical distance and may therefore be more powerful to produce the same effect as a direct, historically perceived, authentic event.

\section{Summary}

In summary, it seems clear to the authors that an argument can and should be made for reconsidering the ubiquity of field and clinical experiences in many disciplines across higher education and vocational training (either for novice professionals or the continued development of career professionals) which situate learners in authentic work settings. These authentic work experiences transfer to human consciousness as sensory data, which are distorted by 
personal, cultural history and bias. These authentic professional experiences are also inefficient and expensive to create and sustain in many locations and in many vocational disciplines. Finally, these authentic experiences frequently lack sufficient quality control mechanisms to stabilize and standardize the experiences in a way that ensures high quality professionals at the career-entry point or sustained and consistent development of professionals across the career.

It seems clear from the authors' research and that of others cited in this paper, that simulations of experience possess the ability to transfer to real-world growth, development, and decision-making. These simulations can be managed and standardized in ways that contribute positively to quality control and to economic efficiencies and replicability. On balance, it should be considered that the epistemic weight of the sensory data from both authentic and simulated experiences are equalized as they move from sensory data to short and long-term memory, and in the translation to cognitive and linguistic processing. And in this case, the argument for efficiencies, standardization, and replicability of the simulated experience would be preferred for vocational education uses over the reliance on authentic field and clinical experiences.

\section{Discussion and Recommendations}

As the authors come to the end of this work and consider the implications of their review of literature and interpretation of the new case example, it is important to "step back" from the immediacy of the current findings and reconceptualize some of our previous work and our path forward. They identify three areas of rich potential for expanding our understanding of reflection and its relationship to experience and cognition.

First, in an early research work, the authors evaluated the validity and reliability of King and Kitchener [7] work on epistemic cognition. In brief, individual professionals have been found to possess varying capacities to reflect on cognitive knowledge or on experience. These levels of reflective capacity have been found to elicit varying responses to external, linguistic prompts for reflective decision-making. In this current paper, the authors trace a path, following Habermas [5] which translates both authentic and simulated experiences linguistically. Experiences and personal reactions become embedded linguistic schema using language that was previously acquired. To the authors, this raises a concern about a variation in capacity to benefit from experiential learning because of prior language acquisition and level. Essentially, the pursuit of meaningful learning from experience may be limited by relative strengths and weaknesses in language ability. This leads to a second focus area for further work.

To the extent that, as Habermas [5] describes and as the authors further suggest, language is the vehicle for embedding experiential learning in memory, and activating those memories for professional action, we must consider the implications of language use and discourse in the formation of schema for experiences across individual variation and group variation. When two individuals experience-either authentically or as simulation an event, they may use similar or differing language to label that experience and to translate it to memory. These variations in discourse may lead to interpretive tension and disagreement derived from language use, and not from distinctions in the event itself. This potential will impact the socio-political frame of work, as individuals and groups may experience communication failure at the signal/signification level even when the livedreality is not discernably different. Pragmatically, in professional fields where standardized responses to events, experiences, or stimuli are critical for student, patient, or client-care, treatment or instructional standards, variation in language facility and discourse skills can lead to gross variations in professional conduct. This potential must be carefully grounded in future research.

And finally, we must consider the potential for objectification and distancing in the use of the various tools that are used to assist cognition. Are these used in ways that optimize the elimination of personal subjectivity and emotional response? Do they aid or impede the translation to language Habermas [5] described in the embedding of memory? As a base example, journaling has been welldiscussed as an effective tool to aid professional reflection toward action. Following the frame of thinking developed in this manuscript, a journal entry that posted an immediate (historically proximate) reaction and conclusion to an eventeither authentic or simulated may be overly influenced by subjective biases and prior misconceptions or beliefs. A more professionally educative use of journaling for professional growth as a tool for reflection may instead be an extensive exposition and description of the event without editorial or conclusory comments. Later, at a point more removed historically from the event, re-reading of the journal entry may yield a more objective reaction that is more helpful for professional action. These possibilities could be studied directly through fairly accessible research designs, and would possess the added benefit of direct transfer to a "best practices" literature for professional training programs.

In conclusion, the consideration of simulations as an experiential method for professional growth and development efforts seems, in this analysis, quite more complex an issue when one considers the implications of linguistics and language development to behavioral coding; the uses of cognitive tools to aid learning; and the manner in which language itself shapes, empowers or impedes the embedding of experience into human memory - and activates that memory for professional and personal action. The authors perceive that, while much progress has been made in highlighting these issues and their relationships, much work remains ahead.

\section{References}

[1] J. Baudrillard, (English translation, 1981). "Simulation and simulacra," Translated into English by Sheila Faria Glaser (1994). Ann Arbor, MI: University of Michigan Press. 
[2] Bearman, M., Greenhill, J., and Nestel, D. (2018) The Power of Simulation: A Large-Scale Narrative Analysis of Learners' Experiences. Medical Education. Retrieved from https://www.ncbi.nlm.nih.gov/pubmed/30334299

[3] W. Benjamin (1934). "Art in an Age of Mechanical Reproduction," Translated into English by Andrew Blunden (1998). UCLA School of Theater, Film, and Television. www.marxists.org/references.

[4] Butvilofsky, S., Escamilla, K., Soltero-González, L., and Aragon, L. (2012) Promoting Reflective Teaching Through Simulation in a Study in México Program. Journal of Hispanic Higher Education, 11 (2), 197-212.

[5] J. Habermas (2005) "Truth and Justification," Cambridge, MA: The MIT Press.

[6] Kim, M., and Shin, J. (2016) The Pedagogical Benefits of SimCity in Urban Geography Education. Journal of Geography, 115 (2), 39-50.

[7] King, P. and Kitchener, K. (1994) "Developing Reflective Judgment: Understanding and Promoting Intellectual Growth and Critical Thinking in Adolescents and Adults," San Francisco, CA: Jossey-Bass Publishers.

[8] Lacueva, A. (2014) Theory and Practice in a Science Education Course for Elementary Teachers. Educational Action Research, 22 (2), 196-220.

[9] Lin, H., and Lin, Y. (2014) Digital Educational Game Value Hierarchy from a Learners' Perspective. Computers in Human Behavior, 30, 1-12.

[10] J. F. Lyotard (1984) "The Postmodern Condition: A Report on Knowledge," Minneapolis MN: University of Minnesota Press.

[11] Mawdesley, M., Long, G., Al-jibouri, S., and Scott, D. (2011) The Enhancement of Simulation-Based Learning Exercises through Formalized Reflection, Focus Groups and Group Presentation. Computers \& Education, 56 (1), 44-52.
[12] Minnery, J., and Searle, G. (2014) Toying with the City? Using the Computer Game SimCity ${ }^{\mathrm{TM}} 4$ in Planning Education. Planning Practice \& Research, 29 (1) 41-55.

[13] Monjelat, N., Mendez-Zaballos, L., an Lacasa, P. (2012) Problem Solving Processes and Video Games: The SimCity Creator Case. Electronic Journal of Research in Educational Psychology, 10 (3), 1493-1522.

[14] Novak, J. D. (1998) "Learning, Creating, and Using Knowledge: Concept Maps as Facilitative Tools in Schools and Corporations," Mahwah, NJ: L. Erlbaum Associates.

[15] Rector-Aranda, A., Raider-Roth, M., Glaser, N., and Behrman, M. (2017) "I had to live, breathe, and write my character": Character Selection and Student Engagement in an Online Role-Play Simulation. Journal of Jewish Education, 83, (4), 280-309.

[16] Schön, D. A. (1983) "The Reflective Practitioner: How Professionals Think in Action," New York, NY: Basic Books.

[17] Schön, D. A. (1987) "Educating the Reflective Practitioner: Toward a New Design for Teaching and Learning in the Professions," San Francisco, CA: Jossey-Bass.

[18] Servey, J. and Wyrick, K. (2018) Teaching Clinical Precepting: A Faculty Development Workshop Using RolePlay. MedEdPORTAL, $14 . \quad$ Retrieved from https://www.mededportal.org/publication/10718/

[19] Wills, K. V., and Clerkin, T. A. (2009) Incorporating Reflective Practice into Team Simulation Projects for Improved Learning Outcomes. Business Communication Quarterly, 72 (2), 221-227. 